\title{
ЛИТОСТРАТИГРАФИЯ И ФАЦИИ ЛОНТОВАСКОГО ГОРИЗОНТА В ЭСТОНИИ
}

Лонтоваский горизонт - наиболее характерное подразделение дотрилобитового нижнего кембрия на обширной территории ВосточноЕвропейской платформы (Стратиграфия..., 1979). Будучи представленными очень индивидуализированной толщей «синих глин», выходящей на поверхность у подножья Балтийско-Ладожского глинта, отложения этого горизонта в результате длительной истории изучения наилучшим образом охарактеризованы в пределах Эстонии, где и располагается стратотип горизонта (г. Кунда). В последнее десятилетие на территории ӘССР завершилась среднемасштабная геологическая съемка, которая сопровождалась планомерным разбуриванием всего осадочного чехла данной территории и вскрыла разрезы лонтоваского горизонта на всю мощность даже в зонах глубокого залегания (рис. $1, A)$. Благодаря этому создалась возможность расчленить отложения горизонта здесь на свиты и пачки, а также выявить закономерную замену сравнительно глубоководных глинистых отложений востока территории более мелководными, отчасти даже литоральными песчаными отложениями в районе западных островов Эстонии. Такой четко выраженный в латеральном отношении фациальный-профиль отложений палеонтологически весьма надежно охарактеризованного горизонта является пока единственным для данной платформы и может служить основанием для разработки седиментационной модели лонтоваского бассейна.

Мощность отложений лонтоваского горизонта в Эстонии колеблется в больших пределах - от 90 мна северо-востоке до полного выклинивания на юго-западе (рис. 1,5 ). Наибольшая мощность - более $90 \mathrm{M}$, установленная в скв. Нарва-68, выдерживается также в западной части Ленинградской и Псковской областей, являясь максимальной для всей северо-западной части Восточно-Европейской платформы. В этих же районах наблюдается и максимум тонкодисперсности отложений (Стратиграфия..., 1979, с. 25). К востоку - в сторону наиболее погруженных участков Московской синеклизы - мощность и глинистость горизонта практически не увеличиваются. Это позволяет сделать вывод о том, что в Эстонии мы имеем дело с весьма полными разрезами горизонта. Косвенно это подтверждается и тем, что ряд окаменелостей из верхней части горизонта (Aldanella kunda, Platysolenites spiralis, $P$. lontova и др.) известны только по разрезам Әстонии. Кроме хорошей изученности здешних разрезов, последнее обстоятельство может быть объяснено и наличием только в данном регионе наиболее молодых уровней горизонта. В пользу этого говорит также распространение лишь в пределах Эстонии - в ее северо-западных районах — регрессивной части горизонта (Менс, Пиррус, 1977), не сохранившейся на соседних территориях из-за значительной постседиментационной денудации. Действительно, верхняя граница лонтоваского горизонта из-за изменения структурного плана на этом рубеже маркируется отчетливой 


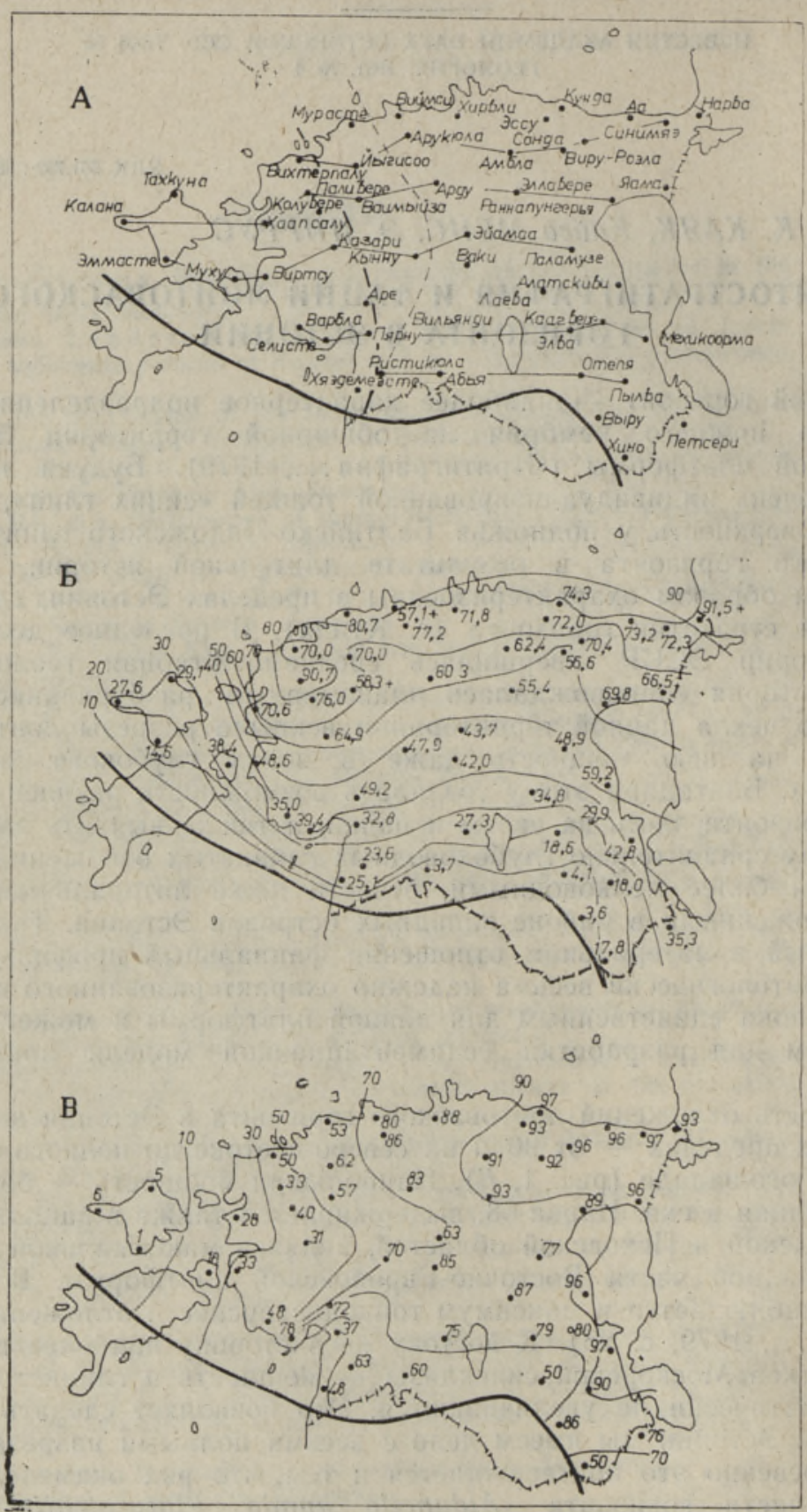

Рис. 1. Лонтоваский горизонт в Эстонин. $A-$ Распространение отложений, расположение изученных скважин и разрезов сопоставления. Жирной линией показана южная граница современного распространения отложений горизонта, сплошной субмеридиональной линией - гранища воозиской и лонтоваской свит, прерывистой - восточная граница распространения таэблаской и казариской пачек. $E$ - Распределение мощности лонтоваских отложений. Изолинии и цифры у скважин показывают мощность горизонта, м. $B$ - Распределение глинистости лонтоваских отложений. Изолинни и цифры у скважин показывают процентное содержание глин в разрезе. 
поверхностью размыва, указывающей на длительное существование денудационных процессов в постлонтоваское время на обширной территории (Палеогеография..., 1980). Денудационным фактором определяется и площадное распределение мощностей горизонта на территории Эстонии, особенно с севера на юг, - в этом направлении последовательно выпадают верхние подразделения разреза вплоть до сохранения только базальных слоев (скв. Абья, Отепя, Выру). В западном направлении мощности сокращаются за счет перехода в более прерывистые мелководные фации, однако плавность этого процесса усложнена локальными участками значительного переотложения в лонтоваском море слабосцементированных песчаников вендского подстила (район скв. Паливере-Вихтерпалу и др.). Поэтому на Северо-Западе Эстонии мощность горизонта находится в достаточно тесной корреляции с песчанистостью разреза (табл. 1).

Лонтоваский горизонт Эстонии сложен исключительно терригенными породами, среди которых преобладают глины, за которыми следуют песчаники. Алевролиты и гравийные породы играют подчиненную роль (табл. 1). Соотношение отдельных типов пород меняется на этой территории очень плавно и хорошо выявляется на карте глинистости горизонта (рис. $1, B)$. Главной тенденцией является уменьшение глинистости разреза с востока на запад, в меньшей степени - с севера на юг. Последняя закономерность отражает не естественную смену отложений в бассейне, а прежде всего отмеченную выше денудацию - последовательный снос на юге верхних более глинистых уровней горизонта.

Принципиальной для горизонта в целом является изолиния глинистости $50 \%$, которая разграничивает области преимущественного распространения глин и песчаников. Она проходит в меридиональном направлении в западной части Эстонии (рис. 1, A и B). Естественно, что западнее этой линии нельзя говорить о толще «синих глин», т. е. о лонтоваской свите, ввиду чего для данного комплекса отложений горизонта предложено название воозиская свита (Кала и др., 1981). При этом следует отметить, что самая западная часть воозиской свиты (западнее изолинии глинистости 10\%) на островах Хийумаа и Вормси уже не содержит органических остатков и ее лонтоваский возраст не доказан. Однако, если проследить послойно отложения с запада на восток, то можно отметить, что они выходят на палеонтологически охарактеризованные лонтоваские отложения в материковой части Әстонии, ввиду чего рассмотрение их в качестве самой прибрежной фации горизонта, на наш взгляд, вполне оправданно.

Несмотря на важное значение изолинии 50\%-ной глинистости, конкретное разграничение латерально заменяющих друг друга лонтоваской и воозиской свит не всегда простое задание, ибо оно усложнено, с одной стороны, постепенной, а с другой, неравномерной сменой главенствующих типов пород в горизонте. Некоторые дополнительные критерии для решения данной проблемы дает анализ внутреннего расчленения как лонтоваской, так и воозиской свит (табл. 2 и рис. 2).

Схема подразделения лонтоваских отложений на пачки разработана в результате прослеживания ассоциаций пород по разрезу и по площади. Основные пачки лонтоваской свиты - махускую и кестласкую - выделил А. Мардла при проведении геологической съемки Северо-Восточной Эстонии. Расчленение свиты в целом существенно пополнилось в результате более поздних работ Э. Кала, С. Мяги, К. Менс, Э. Пирруса в окрестностях г. Таллина. Разбивка воозиской свиты была проведена Э. Кала, К. Менс и Э. Пиррусом (1981) одно- 
Таблица 1

Соотношение типов пород в лонтоваском горизонте

\begin{tabular}{|c|c|c|c|c|c|c|}
\hline \multirow[b]{2}{*}{ Название скважины } & \multirow[b]{2}{*}{$\begin{array}{l}\text { Интервал } \\
\text { залегания }\end{array}$} & \multirow[b]{2}{*}{$\begin{array}{l}\text { Мощ- } \\
\text { ность, } \\
M\end{array}$} & \multicolumn{4}{|c|}{ Содержание пород, \% } \\
\hline & & & $\begin{array}{c}\text { Конгло- } \\
\text { мераты } \\
\text { и гра- } \\
\text { велиты }\end{array}$ & $\begin{array}{c}\text { Песча- } \\
\text { ники }\end{array}$ & $\begin{array}{c}\text { Алевро- } \\
\text { литы }\end{array}$ & Глины \\
\hline
\end{tabular}

Мурасте (Ф-263)

Виймси (8)

Арукюла (40)

Хирвли (8)

Эсcу (208)

Кунда

Aa (Ф-165)

Синимяэ (314)

Нарва (68)

Вихтерпалу (357)

Иыгисоо (Ф-237)

Амбла (Ф-153)

Виру-Роэла

Сонда (Ф-199)

Калана (393)

Тахкуна (396)

Хаапсалу (1)

Паливере (354)

Колувере (12)

Ваймыйза (302)

Арду

Эллавере

Раннапунгерья (76 г)

Яама

Эммасте (400)

Myxy (590)

Виртсу (360)

Казари (16)

Кынну (300)

Эйамаа

Ваки (66)

Паламузе

Варбла (502)

Селисте (173)

Ape (171)

Пярну (11)

Вильянди (91)

Лаэва (18)

Элва

Алатскиви (422)

Kaагвере

Мехикоорма (421)

Хяэдемеэсте (172)

Ристикюла (174)

Абья (92)

Отепя

Пылва (423)

Выру-Реедо

Петсери (330)

Хино (452)

\section{$32,0-112,7$}

$18,6-75,7+$

$95,1-172,3$

$74,2-146,0$

$69,5-141,5$

$14,0-88,3$

$38,0-111,2$

$49,2-121,5$

$19,2-110,7$

$106,4-178,4$

$109,0-179,0$

$190,4-252,8$

$188,0-244,6$

$87,4-157,8$

$193,6-221,2$

$147,0-176,1$

$210,8-281,4$

$219,9-310,6$

$250,1-326,1$

$226,8-285,1+$

$215,6-275,9$

$258,7-314,1$

$173,8-243,6$

$151,6-218,1$

$313,4-328,0$

$368,5-406,9$

$351,4-400,0$

$320,0-384,9$

$354,0-401,9$

$297,9-341,6$

$325,0-367,0$

$333,0-381,9$

$488,0-523,0$

$528,6-568,0$

$397,0-446,2$

$458,5-491,3$

$467,0-494,3$

$373,4-408,2$

$463,2-481,8$

$315,4-374,6$

$397,6-427,5$

$414,2-457,0$

$603,9-629,0$

$546,0-569,6$

$547,3-551,0$

$587,0-591,1$

$489,0-507,0$

$537,4-541,0$

$483,6-518,9$

$553,0-570,8$

\section{0,7}

$57,1+$

77,2

71,8

72,0

74,3

73,2

72,3

$91,5+$

72,0

70,0

62,4

56,6

70,4

27,6

29,1

70,6

90,7

76,0

$58,3+$

60,3

55,4

69,8

66,5

14,6

38,4

48,6

64,9

47,9

43,7

42,0

48,9

35,0

39,4

49,2

32,8

27,3

34,8

18,6

59,2

29,9

42,8

25,1

23,6

3,7

4,1

18,0

3,6

35,3

17,8

\section{$-$}

0,2

0,3

0,3

- 1

-

$-$

$\overline{0,2}$

0,2

0,3
0,1

0,3

$-$

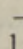

1,7

0,3

0,2

0,2

0,2

\section{-}

$\overline{0,1}$

0,1

$\overline{9,6}$

0,4

0,5

0,8

0,2

0,4

0,6

-

1,2

0,4

0,5

0,8
0,2

$\overline{0,4}$

0,8

-

$\overline{0,6}$

$\overline{0,3}$

$-$
43,4

$\begin{array}{lll}43,4 & 2,0 & 54,6\end{array}$

$\begin{array}{lll}9,8 & 9,8 & 80,2\end{array}$

$\begin{array}{lll}9,7 & - & 86,0\end{array}$

$9,9 \quad 1,5 \quad 88,3$

$6,0 \quad 1,0 \quad 93,0$

$\begin{array}{lll}2,2 & - & 97,7\end{array}$

$3,6 \quad 0,4 \quad 96,0$

$2,0 \quad 1,0 \quad 97,0$

$\begin{array}{lll}6,8 & 0,2 & 93,0\end{array}$

$37,8 \quad 12,0 \quad 50,0$

$\begin{array}{lll}32,3 & 5,7 & 61,7\end{array}$

$9,0 \quad-\quad 90,9$

$7,5 \quad 0,7 \quad 91,5$

$2,4 \quad-\quad 97,6$

$94,5-5,5$

$89,7 \quad 3,8 \quad 4,8$

$\begin{array}{lll}70,0 & 1,7 & 28,0\end{array}$

$65,5 \quad 1,0 \quad 33,3$

$53,8 \quad 6,0 \quad 40,0$

$33,0 \quad 10,3 \quad 56,5$

$9,4 \quad 7,5 \quad 83,1$

$5,7 \quad 1,3 \quad 93,0$

$\begin{array}{lll}9,9 & 0,5 & 89,5\end{array}$

$\begin{array}{lll}4,1 & 0,3 & 95,6\end{array}$

$78,7 \quad 20,0 \quad 1,3$

$49,9 \quad 22,5 \quad 18,0$

$64,4 \quad 2,3 \quad 33,3$

$\begin{array}{lll}67,6 & 1,3 & 30,7\end{array}$

$25,0 \quad 5,0 \quad 69,5$

$28,2 \quad 8,1 \quad 62,9$

$12,4 \quad 4,3 \quad 83,1$

$20,2 \quad 2,1 \quad 77,3$

$\begin{array}{lll}49,7 & 1,7 & 48,0\end{array}$

$\begin{array}{lll}21,1 & 1,2 & 77,7\end{array}$

$25,4 \quad 2,5 \quad 71,9$

$61,9-36,9$

$\begin{array}{lll}22,7 & 1,8 & 75,1\end{array}$

$9,5 \quad 2,9 \quad 87,1$

$16,1 \quad 5,4 \quad 78,5$

$3,5 \quad-\quad 95,7$

$12,7 \quad 7,1 \quad 80,0$

$3,1 \quad-\quad 96,9$

$\begin{array}{lll}49,4 & 2,4 & 47,8\end{array}$

$31,4 \quad-\quad 67,8$

$40,0 \quad-\quad 60,0$

$50,0 \quad-\quad 50,0$

$9,1-90,3$

$13,9-86,1$

$21,9 \quad 2,3 \quad 75,5$

$45,0 \quad 5,0 \quad 50,0$

временно с выделением самой свиты. Материал по пачкам лонтоваской свиты опубликован неоднократно (Кала и др., 1970; Менс, Пиррус, 1977, 1979; Pirrus, 1973), и выделение пачек одобрено Эстонской стратиграфической подкомиссией ПбРМСК. 


\section{Стратиграфическая схема расчленения отложений}

Таблица 2 лонтоваского горизонта Эстонии

\begin{tabular}{|c|c|c|}
\hline \multicolumn{2}{|c|}{ Западная Эстония } & Центральная и Восточная Эстония \\
\hline Свита & Пачки & Пачки \\
\hline
\end{tabular}

Паралепаская

Воозиская
Таммнеэмеская

Кестлаская

Лонтоваская

Махуская

Сямиская

Таэблаская

Согласно вышеотмеченным работам, лонтоваская свита, содержащая всегда более $50 \%$ глин в разрезе и охватывающая центральную и восточную части Әстонии, состоит из четырех пачек (рис. 2, табл. 2). Самая нижняя - сямиская $(\ln \mathrm{S})$ - представлена переслаиванием зеленовато-серых глин, алевролитов и песчаников, содержащих глауконит и гальки фосфатизированных пород. Фациально это наиболее мелководные отложения свиты, соответствующие начальной стадии лонтоваской трансгрессии на данной территории. Следующая, махуская пачка $(\ln M)$, сложена преимущественно зеленовато-серыми алевритовыми и алевритистыми глинами с пленками и гнездами алевритового, реже песчаного материала. Фациально это отражает сравнительно спокойновидные условия глинонакопления, ставшие главенствующими по мере углубления трансгрессии моря. Вышележащая, кестлаская пачка $(\ln \mathrm{K})$, состоит из наиболее тонкодисперсных алевритистых глин трансгрессивного максимума, обладающих характерной фиолетово-серой пестроцветностью. Венчается свита таммнеэмеской пачкой $(\ln \mathrm{T})$, сложенной чередующимися алевритистыми глинами и пелитовыми алевролитами зеленовато-серой окраски. В фациальном смысле эта пачка несет явные признаки регрессии водоема. Таким образом, внутреннее строение лонтоваской свиты хорошо отражает единый крупный цикл осадконакопления на данной территории, что отчетливо наблюдается во всех стратиграфически полных разрезах. Только из-за более глубокой последующей денудации на востоке таммнеэмеская пачка здесь не сохранилась. Следует отметить, что все выделенные пачки лонтоваской свиты имеют весьма индивндуализированную физическую характеристику и поэтому хорошо прослеживаются также на каротажных кривых.

Существенно иное внутреннее строение имеет воозиская свита, сложенная в основном песчаными породами. Однозначно выделяются здесь три пачки. Низы свиты, выделяемые как таэблаская пачка (vs T), характеризуются преобладанием слабоотсортированных, но сравнительно мелкозернистых песчаников, включающих лишь редкие линзы и прослои глинистых пород. Глауконит для-этой части разреза не характерен. Залегающая выше казариская пачка (vs K) сложена в основном также песчаниками и алевролитами, но в отличие от таэблаской здесь породы содержат много глауконита и фосфатизированных галек, и нередко они более грубозернисты. В то же время глинистые прослои в них более мощные (до 3 м) и более выдержанные. Поскольку именно песчаники казариской пачки имеют большое сходство с песчаниками сямиской пачки лонтоваской свиты на востоке, вопрос о фациальной и стратиграфической принадлежности нижележащей таэблаской пачки 

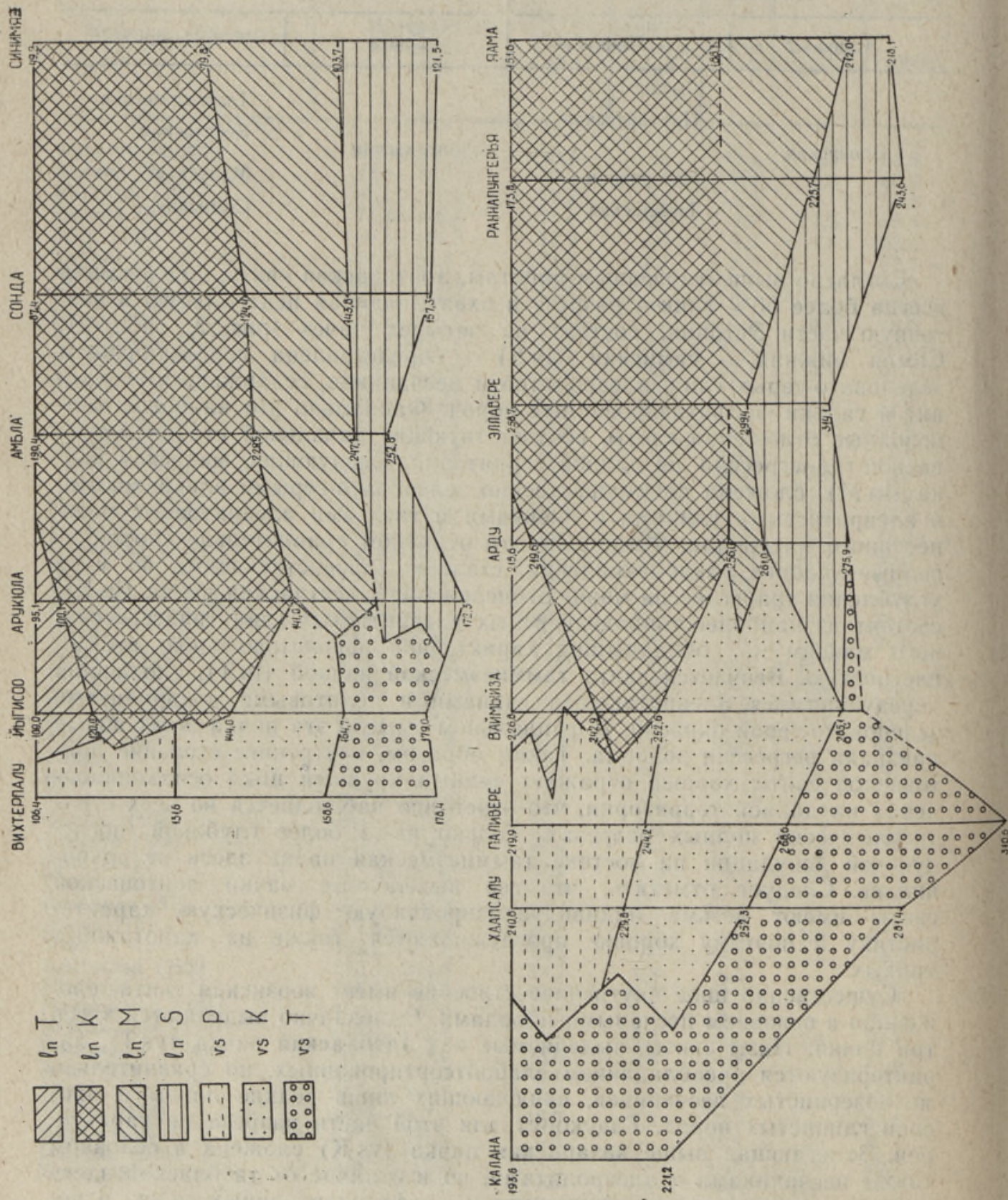
не решается однозначно. Нам кажется наиболее вероятным, что таэблаская пачка соответствует мелководной обстановке начала трансгрессии - периоду переотложения и неоднократного перемыва материала подстила - сравнительно рыхлых песчаников венда. Казариская пачка характеризует уже фазу более развитой трансгрессии - времени, когда в бассейне возникли зоны глауконитообразования в участках затишья, откуда этот минерал позднее был переброшен в сохранившиеся песчаные отложения. Верхняя часть воозиской свиты выделяется как паралепаская пачка (vs P), в которой преобладают глины, в разной степени обогащенные алевритовым материалом. Нередко встречаются прослои алевролитов мощностью до $20-30 \mathrm{~cm}$. В целом паралепаская пачка не обнаруживает прямого сходства с какой-либо глинистой пачкой лонтоваской свиты, как в ней не может быть выделен и один отчетливый максимум глинонакопления. В этом, очевидно, отражаются более мелководные и неспокойные условия седиментации воозиской свиты в целом, о чем свидетельствует большая изменчивость мощности пачек при переходе от одного разреза к другому. На прерывистость осадочного процесса при осаждении воозиских отложений указывают и палеонтологические данные. Если в лонтоваской свите, несмотря на ее большие мощности на востоке, не найдена наиболее молодая окаменелость горизонта - Platysolenites spiralis (Пости, 1978) -, то в воозиской свите при более сокращенных разрезах найдены нередко оба возрастных репера: в низах Sabellidites sp., а в верхах Platysolenites spiralis (скв. Виртсу, Казари и др.).

Таким образом, нет прямых критериев точного сопоставления между собой подразделений лонтоваской и воозиской свит. Однако на стыке этих свит (в районе изолинии глинистости $50 \%$ ) имеются разрезы, низы которых сложены породами, свойственными таэблаской и казариской пачкам, а верхи характеризуются отложениями кестлаской и таммнеэмеской пачек (скв. Иыгисоо, Ваймыйза, Кынну - рис. 2). Начиная с меридиана Таллина сямиская пачка лонтоваской свиты теряет свои признаки и сменяется толщей мелкозернистых песчаников с маломощными прослоями глин (таэблаская пачка). На этой линии выклиниваются также сероцветные алевритовые глины махуской пачки и непосредственно над песчаниками таэблаской пачки появляются слабоотсортированные, иногда крупнозернистые песчаники с глауконитом и прослоями глины (казариская пачка). Гораздо дальше на запад распространяются пестроцветные глины кестлаской пачки и только западнее линии Вихтерпалу-Казари-Пярну они выпадают из разреза, сменяясь комплексом переслаивания глинистых и алевритовых пород (паралепаская пачка). Дальше на запад они уже сменяются однородными песчаными отложениями мелководья и при этом сильно сокращаются в мощности (скв. Эммасте, Калана и др.).

Итак, точное разграничение лонтоваской и воозиской свит имеет явную условность: по верхним уровням разграничительную линию между ними можно провести западнее, чем по нижним. На наш взгляд, выход тут прежде всего в договоренности специалистов. Мы предлагаем провести эту границу по изолинии глинистости $50 \%$ (рис. $1, A$ и $B$ ), которую очень удобно взять за основу при дефиниции свит. В общих чертах эта изолиния совпадает с западной границей распространения наиболее тонкодисперсной пачки лонтоваской свнты (кестлаской). При таком решении проблемы исключение составят разрезы скв. Селисте и Пярну, в которых глинистость более $50 \%$, но попачечное расчленение свиты ближе к таковому в воозиской свите. Следовательно, на стыке двух свит образуется своеобразная переходная зона, 
Рис. 3. Основные фациальные зоны лонтоваского горизонта в Әстонии. I - прибрежно-литоральная, II - мелководноактивная, III - мелководноспокойная, IV - относительно глубоководная, спокойная.

в пределах которой точное разграничение свит не всегда возможно. Однако вполне понятно, что новые скважины помогут решить данную проблему, так как станет возможным детально проследить судьбу отдельных «языков» и реперных уровней. Несомненно, в большей степени будут выявлены и биостратиграфические критерии корреляции, которые сейчас еще малочисленны (см. Менс, Пости, 1981). Однако, нет сомнения, что уже сейчас для лонтоваского времени на территории Әстонии можно наметить основную фациальную зональность, выявляющуюся через распределение преобладающих типов отложений (рис. 3).

Так, первая зона распространяется на самом северо-западе Эстонии и разграничивается изолинией глинистости 10\%. Здесь в лонтоваское время накопились только сравнительно крупнозернистые песчаные отложения, которые неоднократно перебрасывались перед окончательной фиксацией. Коэффициент устойчивости по отношению кварца к полевым шпатам весьма высокий - не менее 10 , а содержание каолинита в цементе песчаников $10-50 \%$ и более. Органические остатки в этих отложениях не обнаружены, найдены лишь единичные ихниты - следы жизнедеятельности типа Planolites диаметром 3 м.. На основе этих признаков можно сказать, что отложения данной зоны накапливались явно в прибрежных, возможно, отчасти в литоральных условиях.

Вторая зона охватывает остальную территорию распространения палеонтологически уже доказанной части воозиской свиты между изолиниями глинистости 10 и $50 \%$. Окраска накопленных здесь песчаных пород, как и в предыдущей зоне, светло-серая, у глин зеленовато-серая. Лишь изредка наблюдаются участки с бледно-фиолетовой пестроцветностью. Коэффициент устойчивости по кварц-полевошпатовому показателю меняется в зависимости от типа пород и никогда не бывает ниже 2. Среди глинистых минералов обладает типично морская ассоциация гидрослюда $(80 \%)$ - хлорит $(5-10 \%)$, и весьма ощутима, особенно у западной границы зоны, доля каолинита (до $25 \%$ и более). Сообщество органических остатков в этой зоне не очень богато по количеству, но разнообразно по содержанию: из лонтоваских форм здесь не найдены лишь рогообразные хитиноидные склериты. Среди ихнитов встречаются как заполненные алевритовым материалом, так и пиритизированные-лентовидные. Наличие ихнитов типа Skolithos, а также многочисленных галек глин и фосфатизированных пород указывает на накопление осадков данной зоны в мелководной подвижной среде с перемывом больших масс ранее отложенных остатков. Глинонакопление как характерный признак лонтоваского осадконакопления не получило в этой зоне существенного развития, и лишь во второй половине лонтоваского времени - в условиях максимальной трансгрессии глинистые отложения стали играть более существенную роль, 
Третья зона охватывает площадь между изолиниями $50-90 \%$. Это фация накопления преимущественно глинистых осадков, которые во время трансгрессивного максимума приобретают высокую дисперсность и характерную фиолетово-серую пестроцветность. Образование последней можно связать с подавлением жизнедеятельности древних организмов в наиболее глубоководных участках бассейна, ввиду чего продуктов разложения их не хватало для полного фронтального восстановления окисных соединений железа при диагенезе и процесс этот развивался по пятнистым очагам. Только в первой половине осадконакопления условия в этой зоне были близкими к неспокойно-мелководным, преобладающим во второй фациальной зоне в течение всего цикла осадконакопления. Коэффициент устойчивости в данной зоне колеблется около 2 и только у песчаников в нескольких разрезах доходит до 10 (скв. Арду). Глинистый компонент гидрослюдистый, с небольшими $(1-10 \%)$, но постоянными примесями как хлоритов, так и каолинита. Следов жизнедеятельности различных организмов много. Среди них явно преобладают горизонтальные следы передвижения, что свидетельствует о тиховодном режиме осадконакопления. Много в глинистых отложениях пиритизированных следов жизнедеятельности, а также фрагментов обычных обитателей лонтоваского моря - сабеллидитид (в низах разреза) и платисоленитид (на более высоких уровнях).

Четвертая фациальная зона охватывает восточную часть территории Эстонии и западные районы Ленинградской и Псковской областей. Для этой зоны характерно очень выдержанное глинонакопление $(>90 \%)$, сопровождающееся широко развитой пятнистой пестроцветностью. Фнолетово-бурые пятна и полосы наблюдаются не только в кестлаской, но и в махуской и сямиской пачках. Коэффициент устойчивости (кварц : полевые шпаты) здесь наиболее низок - обычно меньше 2, в глинах иногда и около 1. Это свидетельствует об одноактности переноса и осаждения тонкого кластогенного материала и о спокойном водном режиме седиментации. В сообществе ихнитов явно превалируют горизонтально расположенные иногда сильно меандрирующие формы. Все. эти признаки однозначно говорят о преобладании наиболее глубоководных и удаленных от берега условий осадконакопления лонтоваского времени именно в этом районе. Об абсолютных глубинах этой зоны осадконакопления сейчас судить весьма трудно, однако можно допустить, что она относится к внутренней части шельфа крупного эпиконтинентального бассейна, где глубины могли достигать 100 и и более.

Выявленная субмеридиональная фациальная зональность лонтоваского горизонта в пределах Эстонии хорошо увязывается с общим палеогеографическим планом лонтоваского времени для всей платформы (Палеогеография ..., 1980) и свидетельствует о близости западной границы водоема к современному Западно-Әстонскому архипелагу. Поэтому выявленные на данном профиле фациальные признаки могут быть использованы для интерпретации ситуации и в других районах платформы, где в лонтоваском горизонте такая зональность выявляется не столь отчетливо.

\section{ЛИТЕРАТ У Р А}

Кала Э., Мардла А., Каяк К. Литолого-фациальная характеристика отложений вендского комплекса и балтийского яруса Эстонин. - Тез. докл. VII на. учной конференции геологов Прибалтики и Белоруссии. Таллин, 1970, 65-68.

К ал а Э. А., М н с К. А., Пир у с Э. А. К стратиграфии кембрия на западе. Эстонни. - В кн.: Стратиграфия древнепалеозойских отложений Прибалтики. Таллин, 1981 . 
Менс К. А., Пир рус Э. А. Стратотипические разрезы кембрия Эстонии. Таллин, 1977.

Менс К. А., Пир рус Э. А. Южный склон Балтийского щита. - В кн.: Стратиграфия верхнедокембрийских и кембрийских отложений запада ВосточноЕвропейской платформы. М., 1979, 7-41.

М ен С. А., Пости Э. А. Распределение и корреляционное значение органических остатков в балтийской серии Эстонии. - В кн.: Стратиграфия древнепалеозойских отложений Прибалтики. Таллин, 1981.

Палеогеографня и литология венда и кембрия запада Восточно-Европейской платформы. М., 1980.

Пости Э. Новые находки платисоленитид и гастропод из лонтоваского горизонта Эетонии. - Изв. АН ЭССР. Геол., 1978, 27, 103-107.

Стратиграфия верхнедокембрийских и кембрийских отложений запада ВосточноЕвропейской платформы. М., 1979.

Pirrus, E. Mida teame sinisavist. - Eesti Loodus, 1973, 11, 646-653.

\author{
Институт геологии \\ Академии наук Эстонской ССР
}

Поступила в редакцию $27 /$ III 1981

\title{
E. KALA, K. KAJAK, Kaisa MENS, E. PIRRUS
}

\section{LONTOVA LADEME LITOSTRATIGRAAFIA JA FAATSIESED EESTIS}

On kirjeldatud lontova lademe lateraalset muutlikkust Eestis paljude puuraukude andmeil ning antud tema kihistute ja kihistike ruumiline levikupilt laiusesuunalistel profiilidel. Materjali analüüs vōimaldab eristada lademe piires 4 fatsiaalset vööndit, mille seaduspärane vahetumine läänest itta loob ettekujutuse lontovaaegse mere settimismudelist ja on seetōttu kasutatav paleogeograafilise olustiku rekonstrueerimisel teisteski rajoonides. Madalaveeline rannalähedane vöönd on kõige paremini välja kujunenud läänesaarte pōhjaosas, rannast kõige kaugemal asunud rahulik süvaveeline settimisala Ida-Eestis. Nende vahel olevatel vöönditel on setete kuhjumise hüdrodünaamika näitajate poolest siirdeline iseloom.

\section{E. KALA, K. KAJAK, Kaisa MENS, E. PIRRUS}

\section{LITHOSTRATIGRAPHY AND FACIES OF THE LONTOVA STAGE IN ESTONIA}

The article deals mainly with lateral variability in the lithological composition of the deposits and shows how this has been reflected in the subdivision of the stage. Figure 1 gives the distribution of Lontovian deposits together with the localities of the most important boreholes (A), their thickness in meters (B) and content of clay (B).

The stratigraphical completeness and thickness of the stage in the studied area show a great variety towards the south due to post-sedimentational denudation. In East and Central Estonia, the Lontova Stage is represented by the Lontova Formation consisting predominantly of claystones. In West Estonia, the Lontova Stage is represented mainly by sandstones and defined as the Voosi Formation. In Fig. $1, A$ the boundary between these formations is indicated by a continuous line, coinciding rather accurately with the $50 \%$ content isoline of claystones (Fig. 1,B).

According mostly to the relative abundance of rock types and to lithological features of deposits, the formations are subdivided into members (Table 2). The Lontova Formation includes four members: the Sämi $(\ln S)$, Mahu $(\ln M)$, Kestla $(\ln \mathrm{K})$ and Tammneeme $(\ln \mathrm{T})$ members. The Voosi Formation has been divided into three members: Taebla (vs T), Kasari (vs K) and Paralepa (vs P). The replacement of the units of the Lontova Formation by the members of the Voosi Formation along several latitudinal key sections is presented in Fig. 2.

The lateral distribution of the sediments is quite clearly zonal. These zones differ from each other in the ratio of rock types. The zonal distribution of sediments is accompanied by changes in their mineral composition and fossils. The lateral arrangement of the sediments suggests an increasing of deep water sedimentation conditions in the direction from west to east. On the basis of the results of lithostratigraphical investigations, a lithofacial map of the Lontova Stage (Fig. 3) has been drawn. 